Reprod. Nutr. Dévelop., 1986, 26 (1 B), 317-318.

\title{
Teneur en ARN du jus de rumen et du contenu de duodénum
}

\author{
F. LAURENT, J. BRUN-BELLUT, B. VIGNON
}

Département Sciences animales, E.N.S.A.I.A.,

2, avenue de la Forêt de Haye, 54500 Vandouvre, France.

Summary. RNA content in duodenal digesta with a rye grass or a rye grass + concentrate diet was more variable than in rumen juice. Microbial nitrogen was 74 or $68 \%$ of the non-ammoniacal nitrogen in the duodenum. Microbial synthesis was 143 or $148 \mathrm{~g}$ of crude protein $/ \mathrm{kg}$ DOM. Urinary allantoin nitrogen represented 58 or $61 \%$ of the apparent amount of N-RNA digested in the gut.

Afin de quantifier la synthèse bactérienne dans le rumen et le flux de protéines microbiennes transitant dans le duodénum, nous mesurons les teneurs en ARN. Ayant observé dans des essais antérieurs (Laurent et al., 1984) que la teneur en ARN du jus de rumen des moutons variait plus en fonction de l'heure de prélèvement que des régimes alimentaires utilisés, nous avons poursuivi l'étude de ses variations au cours du nycthémère dans des conditions différentes: chez une chèvre en lactation et chez un mouton à l'entretien. Nous présentons les premiers résultats de ces nouveaux essais.

Matériel et méthode. Du ray grass anglais ( $3^{e}$ cycle, $14 \%$ de MAT) est distribué en vert ad libitum en 2 repas ( $8 \mathrm{~h}$ et $17 \mathrm{~h}$ ) à un mouton à l'entretien (RGA) et à une chèvre en lactation, celle-ci recevant en outre $400 \mathrm{~g}$ d'orge et $100 \mathrm{~g}$ de tourteau de soja (RGA $+C$ ). Les animaux porteurs de canules simples du rumen et du duodenum sont placés en cage à digestibilité.

Les flux dans le duodenum sont mesurés par double marquage au PEG 4000 $(30 \mathrm{~g} / \mathrm{j})$ et à l'oxyde de chrome $(2 \mathrm{~g}$ de papier chromé $/ \mathrm{j})$ : les marqueurs sont introduits directement dans le rumen matin et soir, au moment des repas, pendant 20 jours. Les prélèvements de contenu de duodénum $(150 \mathrm{ml})$ ont lieu le $21^{\mathrm{e}}$ jour, juste avant le repas du matin puis toutes les $3 \mathrm{~h}$ pendant $24 \mathrm{~h}$, ceux de jus de rumen toutes les $4 \mathrm{~h}$ le $22^{\mathrm{e}}$ jour. Pour chaque prélèvement sont déterminés le $\mathrm{pH}$, les teneurs en matière sèche, en azote total, en azote ammoniacal et en ARN (Ben Ghedalia, 1981). Les bactéries sont préparées selon la méthode de Smith et Mc Allan (1974). La concentration en PEG est déterminée par turbidimétrie, la teneur en chrome par spectrophotométrie. Les bilans azotés sont mesurés entre le $10^{\mathrm{e}}$ et le $20^{\mathrm{e}}$ jour ainsi que la teneur moyenne en $A R N$ des fécès congelés et l'excrétion quotidienne d'allantoine urinaire (Laurent et Vignon, 1983).

Résultats et discussion. Les principaux résultats sont rassemblés dans le tableau 1. Les teneurs moyennes en ARN sont de 12,8 et $10,5 \mathrm{mg} / \mathrm{g}$ de matière sèche du jus de rumen respectivement pour les régimes $R G A+C$ et RGA. Par rapport aux essais antérieurs l'heure de prélèvement a moins d'influence sur la teneur en ARN (coefficient de variation de $6 \%$ contre 10 à $15 \%$ ) et la part de $\mathrm{N}$ - 
ARN dans le $\mathrm{N}$ total est plus faible. La nature du régime (MAT/MO égal à 17$18 \%$ contre 9 à 13) et la fréquence des prélèvements (intervalle de $4 \mathrm{~h}$ sur $24 \mathrm{~h}$ au lieu de $2 \mathrm{~h}$ sur $9 \mathrm{~h}$ ) peuvent expliquer ces différences.

Dans le contenu du duodénum, il $n^{\prime} y$ a pas de liaison entre les teneurs en $N$ total, $\mathrm{N}-\mathrm{NH}_{3}$ et $\mathrm{N}-\mathrm{ARN}$. Les variations de la teneur en ARN en fonction de I'heure de prélèvement sont importantes (tabl. 1). Les teneurs moyennes sont de 16,2 et $19,3 \mathrm{mg} / \mathrm{g}$ de MS du contenu respectivement pour RGA + C et RGA.

TABL. 1. - Quantités ingérées, teneur en ARN du jus de rumen et du contenu de duodénum, composition du contenu de duodénum, flux d'ARN et excrétion d'allantoïne.

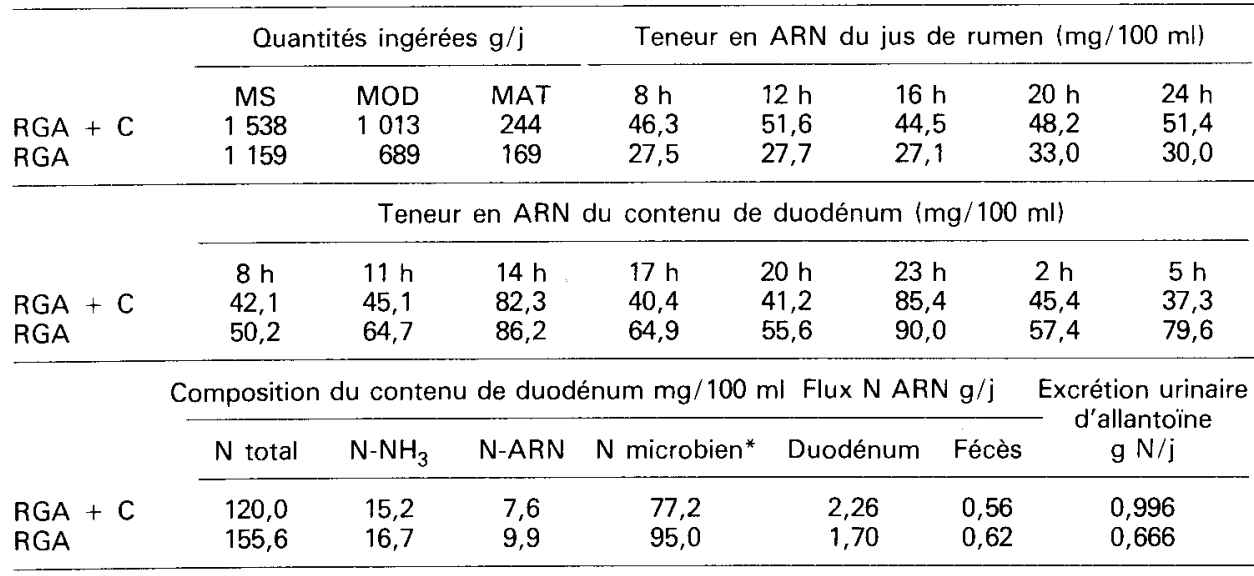

*NARN/N total des bactéries RGA + C : 8,37 - RGA:8,86\%; $15 \%$ de I'ARN du duodénum est d'origine alimentaire (MacAllan 1982).

L'azote microbien représente respectivement 74 et $68 \%$ de l'azote non ammoniacal du duodénum pour les régimes RGA + $C$ et RGA. La synthèse de matières azotées microbiennes calculée est égale à 143 et $148 \mathrm{~g} / \mathrm{kg}$ de matière organique digestible. L'excrétion urinaire d'azote de l'allantoine représente 58 et $61 \%$ de la quantité d'azote purique apparemment digérée dans les intestins. Ces premiers résultats sont à vérifier sur un plus grand nombre d'animaux.

Ben Ghedalia D., 1981. Fate of digesta ribonucleic acid in small intestine of sheep. J. Dairy Sci., 64, 2422-2425.

Laurent F., Vignon B., 1983. Veränderungsfaktoren der Allantoinausscheidung bei Schafen und Ziegen. Arch. Tierernähr, 33, 671-681.

Laurent F., Blanchart G., Vignon B., 1984. Teneur en acide ribonucléique du jus de rumen de moutons. Can. J. anim. Sci., 64 (suppl.), 43-44.

McAllan A. B., 1982. The fate of nucleic acids in ruminants. Proc. Nutr. Soc., 41, 309-317.

Smith R. H., McAllan A. B., 1974. Some factors influencing the chemical composition of mixed rumen bacteria. Br. J. Nutr., 31, 27-34. 